\title{
EVALUACIÓN Y GERENCIA PARTICIPATIVA DE LOS APRENDIZAJES EN EL AULA. UNA MIRADA EN LA PRÁCTICA EVALUATIVA EN EL TIEMPO
}

\author{
Blanquita Concepción García García \\ Docente, Investigadora la Universidad del Zulia, Núcleo LUZ-Punto Fijo \\ Punto Fijo, Venezuela \\ María Lourdes Piñero Martín \\ Docente, Investigadora de la Universidad Pedagógica Experimental \\ Libertador-Instituto Pedagógico de Barquisimeto \\ Barquisimeto, Venezuela \\ Teodoro Pinto Iglesias \\ Docente jubilado de la Universidad del Zulia \\ Punto Fijo, Venezuela \\ Alfonso Carrillo Vásquez \\ Docente de la Universidad Nacional Politécnica Experimental, \\ Antonio José de Sucre \\ Barquisimeto, Venezuela
}

Recibido 24-I-2009 • Aceptado 30-V-2009 • Corregido 31-VIII-2009

"El mejor educador, el ejemplo"

A. Einstein

Resumen: El presente artículo es de naturaleza descriptiva-explicativa con un abordaje documental. En él se esbozan las principales teorías y enfoques relacionados con la evaluación de los aprendizajes, en línea con el tiempo de su aparición, para luego configurar un escenario de la gerencia participativa en el aula desde la mirada de la práctica evaluativa como parte constitutiva del proceso de enseñanza y aprendizaje que, a su vez, implica la asimilación del conocimiento con la consecuente transformación.

\section{Introducción}

La evaluación educacional, entendida como la comprobación del grado en que los estudiantes han alcanzado las competencias previstas, adquiere valor y vida pedagógica en función de su utilidad para la toma de decisiones que mejoren el proceso educativo, 
Se asume una gerencia participativa con miras a propiciar un ambiente lo suficientemente dinámico, interactivo, crítico y reflexivo que permita la búsqueda de la calidad y la excelencia en el aula. Se propone un enfoque de la gerencia de los aprendizajes en el que cada uno de los actores educativos asume el liderazgo compartido en la planificación, organización, dirección, evaluación y realimentación, el cual se desarrolla en un ambiente de comunicación, reflexión crítica $y$ autorregulación durante el proceso que implica la construcción y reconstrucción de los saberes y el desarrollo de competencias.

Palabras clave: Evaluación, didáctica, calidad, gerencia en el aula, aprendizaje.

Abstract: This article is descriptive-explanatory with a documentary approach. It outlines the main theories and approaches to the assessment of learning, in line with their time of appearance, and then set up a scenario for participative management in the classroom from the perspective of the evaluation practice as a constituent part of teaching and learning process, which in turn implies the assimilation of knowledge and the consequent transformation of the participants. Participatory management is assumed in order to promote a dynamic, interactive, critical and reflective environment, allowing the pursuit of quality and excellence in the classroom. It proposes an approach to management of learning in which each of the educational actors assume shared leadership in planning, organizing, directing, evaluation and feedback, which takes place in an atmosphere of communication, critical thinking and self-regulation during the process that implies the construction and reconstruction of knowledge and skills development in teaching and learning processes.

Key words: Evaluation, didactics, quality, management in the classroom, education. el cual, coincidiendo con lo planteado por García (1999), será entendido como el proceso enseñanza, aprendizaje, asimilación y transformación (EAAT) ${ }^{1}$ que repercute en el mejoramiento de la educación, lo que finalmente mejora también la calidad de vida de cada habitante y de la sociedad en general. Es importante entonces precisar una metodología de calidad total del proceso educativo en cuyo contexto se ha de tomar en cuenta la gerencia desde el aula, la cual permite la evaluación integral, sincronizada y armónica de todos los actores y elementos que participan en el proceso educativo. Estos son, a saber, estudiante, docente, fines, competencias educacionales y estrategias didácticas tanto para aprender como para conducir los aprendizajes. En este orden de ideas, el presente artículo, de carácter descriptivo-explicativo con abordaje documental, incluye las acciones e indicadores para el diseño de una propuesta con una metodología para la calidad y gerencia del aula en concordancia con la evaluación.

La evaluación en su significado más general es tan antigua como el hombre mismo. Tomar en cuenta indicadores para determinar características y valía de las actuaciones concretas o manifestaciones conductuales de las personas es el denominador común de todas las evaluaciones. En la vida ordinaria, la mayoría de ellas se realiza asistemáticamente, sin que haya un proceso, por una parte, de corrección de debilidades y amenazas y, por la otra, de afianzamiento de fortalezas y aprovechamiento de las oportunidades. Se puede afirmar que la evaluación de la conducta del ser humano depende de los factores estructurales -el humano es una unidad bio-psico-social y coyuntural-, esto es, dónde y cuándo se ejecutan las acciones. Esta realidad ha de tomarse en cuenta en la evaluación educacional puesto que, al fin de cuentas, lo que se evalúa es la conducta de los seres humanos, los estudiantes, con la finalidad última de su continuo perfeccionamiento y 
a la que puede denominarse mejora de la calidad de vida individual y social.

Se puede afirmar que la evaluación de la conducta del ser humano depende de los factores estructurales -el humano es una unidad bio-psico-social y coyuntural-, esto es, dónde y cuándo se ejecutan las acciones. Esta realidad ha de tomarse en cuenta en la evaluación educacional puesto que, al fin de cuentas, lo que se evalúa es la conducta de los seres humanos, los estudiantes, con la finalidad última de su continuo perfeccionamiento y a la que puede denominarse mejora de la calidad de vida individual y social.

Lafourcade (1973), un experto que se ha convertido en un clásico sobre evaluación, se refiere a ella como un proceso sistemático destinado a lograr cambios duraderos y positivos en las conductas de los sujetos sometidos a una influencia, con base en objetivos definidos de modo concreto y preciso, social e individualmente aceptables, dignos de ser cumplidos por los individuos en crecimiento y promovidos por los responsables de su formación.

De Mattos (1974), otro maestro de la evaluación y la didáctica, establece que esta consiste en la suma de las transformaciones que se operan en diferentes áreas, entre las cuales destacan: el pensamiento, el lenguaje técnico, la manera de obrar y la forma de comportarse de los educandos. En estos ámbitos cada evaluación debe incidir en la manera de comprender las situaciones específicas para la resolución de problemas reales sabiendo interpretar y utilizar el lenguaje y sus símbolos, lo que es manifestado en las actitudes y la dinámica afectiva con que se reacciona a situaciones como individuos conocedores y esclarecedores.

Cuando formularon sus apreciaciones sobre la evaluación de los aprendizajes, tanto Lafourcade como De Mattos se movían fundamentalmente en el contexto del neoconductismo skinneriano adaptado por Bloom, Hastings y Madaus (1975) a la comprensión y manejo de docentes. Hoy, la pedagogía se mueve en el contexto del constructivismo, cuya expresión, dentro del escenario de una pedagogía de la liberación -nadie educa a nadie; nadie se educa a sí mismo; los humanos se educan entre sí, mediatizados por el mundo que les rodea-se podría extrapolar a la evaluación: nadie evalúa a nadie; nadie se evalúa a sí mismo. Los sujetos del proceso educativo se evalúan entre sí, mediatizados por el sistema educativo. Es decir, la evaluación educacional, sin dejar comprobar el grado en que los estudiantes han alcanzado las competencias previstas, toma en cuenta todos los elementos que intervienen en el proceso educativo. El punto de partida es la actividad del aula, la cual necesita ser didácticamente conducida, como escribiría un pedagogo clásico, o gerenciada, como gustan decir los escritores modernos de pedagogía.

A la luz de los planteamientos anteriores, la evaluación es parte integrante y constitutiva del proceso enseñanza-aprendizaje que, para estar blindado, requiere de la asimilación (cuando se hace propio el conocimiento) y de la transformación (cuando se evidencian los cambios destacando que el proceso educativo queda inconcluso). Sin la actividad evaluativa, el proceso queda incompleto, al menos por la carencia de certeza de que el proceso haya sido exitoso y de que se haya logrado adquirir las competencias previstas que van a perfeccionar integralmente al educando y a mejorar su calidad de vida y la de quienes viven a su alrededor.

La evaluación, en este contexto, no es una actividad aislada y con propósitos de completitud solamente, sino también un proceso -conjunto de actividades concatenadas- que implica búsqueda, obtención y análisis de información sobre la calidad del aprendizaje del estudiante, sobre la calidad y la conducción que de este realiza el maestro o profesor, sobre el entorno o circunstancias en que se desarrolla el proceso de aprendizaje, sobre el logro de las metas propuestas o su eficacia y sobre el aprovechamiento de los recursos disponibles o su eficiencia, para que, en una especie de círculo virtuoso, se tomen decisiones que cada 
día vuelvan más eficaz y eficiente el proceso educativo.

El proceso evaluativo tal como aquí se concibe no lo puede realizar el maestro o profesor únicamente. En teoría, el maestro o profesor y los estudiantes, todos y cada uno, son los protagonistas del proceso evaluativo de los aprendizajes, pero además participan también otros miembros de la comunidad educativa, sobre todo los adultos significativos para el escolar, los cuales comúnmente y en general son los padres y representantes de cada alumno. En este sentido, la evaluación se convierte en un aporte sustancial para el desarrollo de la personalidad de los individuos inmersos en el proceso de la enseñanza, aprendizaje que es completo cuando el estudiante lo asimila y se opera en él una transformación positiva.

El presente artículo incluye el abordaje teórico a manera de pinceladas en la línea histórica del tiempo además de algunas orientaciones que, con visión de futuro, servirán de apoyo para sustentar la dimensión y dirección de los cambios necesarios a introducir de forma urgente en la evaluación educativa en el aula, al plasmar una metodología ideada para realizarla como un proceso integral, innovador, dinámico, coherente, holístico y participativo dentro de la didáctica educativa. Todo esto sin olvidar que no se da sola, sino que es parte de una concepción educativa que va a marcar la didáctica.

\section{Evaluación de los aprendizajes. Pinceladas en la línea histórica del tiempo}

En muchos contextos, la mención de la palabra evaluación involucra la dirección del pensamiento hacia la palabra examen; a manera de ejemplo, el Antiguo Testamento tiene referencias relacionadas con la evaluación, de las cuales se destaca el Salmo 139:23 (1995): "Examíname, oh Dios, y conoce mi corazón; Pruébame [sic] y conoce mis pensamientos". Y es que al remontarse al tiempo pasado y evocar el nacimiento de la evaluación, se establece un cordón referencial hacia los primeros exámenes competitivos y públicos realizados, algunos de los cuales fueron realizados en la China Milenaria y utilizados, según Fernández Sierra (1994), para seleccionar los miembros del gobierno en la dinastía Han. No obstante, más allá de la noción de "medición" de la evaluación, la palabra se ha asociado también con otros sinónimos como clasificar, estimar, comparar, informar, apreciar, interpretar, controlar, entre otros.

En la antigua Esparta la evaluación de los aprendizajes tenía como finalidad seleccionar los más adecuados para la guerra y las artes marciales para defender al Estado de sus enemigos; mientras que en Atenas se seleccionaba a los más competentes para sobrevivir en el ágora, es decir, en la vida pública, pues el Estado se construía y defendía más en el debate público de las leyes -explicitación de lo racional- que en los campos de batalla; por otra parte, en Roma, utilitarista y sincretista, según el dicho, se aprendía "non scholae sed vitae", "no para la escuela (el examen) sino para la vida" y evaluaban con base en la formación política (a los retóricos) y militar (a los militares).

La irrupción del cristianismo y las invasiones del Imperio romano de occidente enterraron más de mil años de cultura y surgió una nueva concepción del hombre, del mundo, de la sociedad y de la política. El teocentrismo y la teocracia impusieron una nueva didáctica y también una nueva evaluación o forma de otorgar licencia para enseñar en cualquier parte o en los territorios definidos de una monarquía; esta es, a saber, la defensa de la tesis mediante la formulación de un silogismo, a poder ser en $B A R B A R A$, es decir, tanto la premisa mayor como la menor habrían de ser proposiciones universales afirmativas para que la conclusión fuera apodíctica o irrefutable. Era todo un razonamiento deductivo, en muchos casos apriorístico como el argumento ontológico de San Anselmo 
de Canterbury (1998) para demostrar la existencia de Dios, y en otros con base en la realidad como las cinco vías de Santo Tomás. Descartes, Leibniz, entre otros, que fueron entusiastas de argumentos ontológicos; otros pensadores lo rechazaron como prueba válida para demostrar la existencia de Dios, entre ellos, Santo Tomás de Aquino quien no parte a priori, sino de la observación elevada a la condición de principio o, para continuar con el método deductivo, elaboró su propia formulación.

Aunque los invasores del Imperio romano de occidente enterraran la cultura grecorromana, ella renació en el siglo XV e introdujo con gran fuerza al hombre como centro del "quehacer y qué pensar". En función del hombre se desarrollaron las ciencias básicas: Matemática, Física y Biología, y aparece un nuevo método de conducción de los aprendizajes y de la investigación, a saber, la inducción. En este orden de ideas, conviene hacer referencia a Vives (14521540), quien en sus obras de psicología y pedagogía "De anima et vita" y "De trandendis disciplinis" afirma que la instrucción o aprendizaje debe iniciarse por los sentidos y pasar por la imaginación hasta llegar a la razón, iniciando así el método inductivo que desarrollará Bacon (1561-1626) en su obra Novun organum o indicaciones relativas a la interpretación de la naturaleza (1620). Así se inicia el método moderno de investigación científica frente al método filosófico (Bacon, 2004).

Según información de la Ratio Studiorum Oficial (1599), la reforma Protestante y la Católica fueron la reacción respectiva a los excesos del Humanismo renacentista, y si bien teológicamente tenían diferencias insalvables para entonces, en las concepciones didácticas y en las realizaciones educacionales mostraban sorprendentes coincidencias. Para consolidar la respectiva reforma y para impedir que la otra ganara terreno nada más apto que la educación de la infancia y de la juventud. Los maestros habían de reclutarse entre los mejores alumnos y habían de estar sometidos a un proceso de actualización. Al Provincial de los Jesuitas se le encomendaba que cuidara la selección, actualización y perfeccionamiento constante de todos los maestros o profesores. Los exámenes eran estrictos y obligatorios y había premio para quienes presentaran los mejores trabajos en retórica, prosa latina, gramática, entre otros.

Comenio (1971), teólogo y pedagogo protestante, establece cuatro tipos de escuela "conforme a las edades y aprovechamiento". En la "escuela común”, equivalente a la escuela básica o primaria, a fin de asegurar los conocimientos adquiridos "se establecerán concursos o certámenes sobre quién es el que recuerda antes y mejor todo lo explicado, o escribe, numera o canta con menos equivocaciones" (p. 286).

Cabe destacar que el método inductivo de investigación potenció el desarrollo de las ciencias modernas y pudiera decirse que llegó al culmen con el Positivismo de finales del siglo XIX y principios del XX. Se aplicó lo que se venía proponiendo desde la teoría de Sócrates pasando por Quintillano, Vives, Comenio y tantos otros pedagogos, a saber, considerar el hecho educativo en su contexto y considerarlo como un proceso en el cual la evaluación o los exámenes son parte integrante del proceso en que, si bien se establecen ciclos, esto se hace sólo con fines administrativos, pues la educación es un proceso continuo. La evaluación educacional es en sus múltiples formas y modalidades una evaluación institucional de los aprendizajes de la administración educacional, de la gerencia en el aula.

La invención de la imprenta en 1450 facilitó enormemente la divulgación del conocimiento y se convirtió en un competidor fuerte con el maestro. Empezó la crisis del "magister dixit", los alumnos cada vez tenían más posibilidades de acceder a las fuentes de información. Así fueron dándose la industrialización de la imprenta, el desarrollo de los medios de comunicación, los "mass media", permitiendo el alcance de la información a un mayor público y dentro de él a los estudiantes. 
Tyler (1949) uno de los teóricos de la evaluación educativa, reconocido mundialmente por sus estudios de la evaluación por objetivos. Para él, el objetivo del proceso evaluativo era determinar el cambio ocurrido en los alumnos a la vez que servía de informante sobre el programa educativo.

En los sesenta, el énfasis estaba en la toma de decisiones y la valoración formativa de la evaluación, tal como lo expresan sus representantes, entre los cuales Bloom et al. (1975), proponente en 1956 de diferentes niveles para la ubicación taxonómica de los objetivos. Suchman (1967), otro exponente, propone que los datos deben ser objetivos y analizados con metodología científica; a su vez, Alkin (1973) centra la atención en los productos mesurables. Por su parte, Scriven (1974), con publicaciones desde 1967, y Rowntree (1977) exponen criterios fundamentados en mayores canales para la obtención de la información requerida para el proceso de evaluación, conducentes a tres tipos de evaluación: diagnóstica, formativa y sumativa.

También surgen los enfoques naturalistas cualitativos en la concepción de la evaluación educativa fundamentada en procesos compresivos, interpretativos y críticos, con el fin de generar información derivada de la práctica desde la acción dialógica, intersubjetiva, participativa y reflexiva tanto del docente como los alumnos; estos enfoques permiten direccionar la construcción de los aprendizajes.

Cronbach (1963) plantea la importancia de la búsqueda de información clara, oportuna, precisa, válida y amplia; el autor aborda una noción de evaluación con especial referencia a la búsqueda de datos y a la comunicación a los encargados de la toma de decisiones. Por otra parte Scriven (1974) presenta planteamientos relacionados con el valor de la enseñanza (formativa y sumativa); suyo es el modelo evaluativo "orientado al consumidor". En su teoría considera que la evaluación formativa está al servicio de un programa en desarrollo para mejorarlo y la sumativa para comprobar la eficacia de este luego de su aplicación. Establece diferencias entre la evaluación intrínseca y la evaluación extrínseca. Objeta a Cronbach y establece la importancia de los estudios comparativos. También es proponente del modelo basado en el Modus Operandi (MO) y, además, de plantea la importancia de la evaluación libre de metas, para lo cual considera tres fases como relevantes: recopilar la información, contrastar las inferencias y comprobar los efectos del Programa.

Siguiendo la línea histórica del tiempo, se referencian las ideas de Parlett y Hamilton (1989), quienes hablan de la llamada evaluación iluminativa, la cual se complementa con la importancia de la observación del todo, el sujeto y el contexto. En esta percepción, se hace la identificación con un paradigma de investigación antropológica centrada en el análisis de los procesos de negociación que tienen lugar en el aula. Esta determina que los procesos en movimiento son cambiantes, y que debe haber una evaluación efectiva a partir de la familiarización intensiva con los problemas. La evaluación es consecuencia del pacto y la negociación, lo que implica apertura y flexibilidad metodológica utilizando, entre otras opciones, la observación, la entrevista, el análisis documental y los cuestionarios. Este modelo rompe el convencionalismo cuantitativo y contempla ciertas características, entre las cuales destacan: el estudio holístico del contexto, una mayor relevancia a la descripción e interpretación, la fundamentación en los procesos, la evaluación realizada en un ambiente natural o de campo y una metodología cualitativa.

Sthenhouse (1991, 1996), considerado como uno de los grandes pedagogos del siglo XX, tiene entre las aportaciones de sus estudios de la década de los setenta la aplicación de la investigación-acción, en la cual la teoría y la práctica deben estar unidas. Considera como indispensable el tener un conocimiento profundo sobre los 
cambios que se desean en los alumnos, ideas que coinciden con las de otros teóricos, que también teorizaron sobre la investigaciónacción en la Educación.

En este orden de ideas, destacan los trabajos de Stake (2006) quien incluye planteamientos sobre la evaluación comprensiva y la evaluación basada en estándares. Concibe el proceso como pluralista, flexible, holístico y con orientación al servicio con especial referencia a los antecedentes, procesos, normas y juicios. Además, considera como propósito prioritario el responder a los problemas y cuestiones reales. El modelo de Stake se denomina evaluación respondiente y tiene tres aspectos básicos que son: 1 . Observación y mejoramiento continuo del quehacer diario. 2. Programas elaborados por los docentes que parten de los antecedentes donde todo es importante, tanto los efectos secundarios como los hallazgos accidentales, los cuales tienen tanta importancia como los resultados esperados. 3. Todos los allegados al proceso pueden participar como evaluadores.

En cuanto al afianzamiento del estudio de casos en la práctica evaluativa, autores como Kemmis (1998) proyectan la evaluación con la interacción de todos los componentes de la educación; la interacción incluye así el currículo, los administradores, alumnos y programas. Este autor plantea un modelo que tiene especial atención en la evaluación orientadora, la cual está centrada en valores o principios rectores, entre los cuales destaca la racionalidad, autonomía, responsabilidad, intereses, entorno, pluralidad de criterios, oportunidad y adaptación. Por otra parte, MacDonald (1989) propone la evaluación democrática con puntos coincidentes con las ideas de Sthenhouse (1996), estos referidos a la evaluación de la vida del aula por medio de la aplicación de planteamientos y procedimientos metodológicos naturalistas. El autor plantea que en este tipo de evaluación hay una necesidad de cambiar la perspectiva ecológica y contextual, y que es de suma importancia la información que en definitiva permite la toma de decisiones.

Eisner (1998), quien desde 1987 establece la evaluación como actividad artística y creativa realizada por un experto (el docente), teoriza sobre la descripción, interpretación y la valoración entrando en niveles de mayor participación. Autores como Guba y Lincoln (1989) presentan elementos en los que se pone de manifiesto la evaluación respondiente y constructivista, con especial insistencia en que el currículo necesita organizarse en torno a unos objetivos, los cuales constituyen la base de la planificación al servir de guía a los docentes como criterio para la selección de materiales, concreción de contenidos que a su vez permiten desarrollar procedimientos de instrucción para la posterior preparación de exámenes. Otros teóricos como Von Glaserfeld (1988) exponen sus ideas sobre el Constructivismo, mientras que otros como Posner (1998) plantean que la evaluación debe ser colaborativa.

Entre los autores con mayores aportaciones destacan Stufflebeam y Shinkfield (1987) y Shinkfield y Stufflebeam (1995) quienes durante más de tres décadas realizaron planteamientos relacionados con el perfeccionamiento de la enseñanza con la particularidad de centrar la evaluación en el proceso y no en los resultados, y definió la evaluación como el proceso de delimitar, obtener y proveer de información útil para juzgar entre alternativas de decisión. Otros autores como Guba y Lincoln (1989), establecieron el modelo de los cuatro momentos de actuación de la evaluación: Contexto, Input, Proceso y Producto, conocido por sus siglas (CIPP). Stufflebeam y Shinkfield (1987) y Shinkfield y Stufflebeam (1995) aportan elementos de referencia para la evaluación sistemática. Por su parte, House (2000) estudió la factibilidad de ubicación en el contexto educativo de los programas de intervención social.

Obviamente que el hilvanar una línea del tiempo de la evaluación en 
los diferentes momentos de la historia obligaría a una exhaustiva revisión y contrastes, lo cual no es el objeto del presente trabajo. Sin embargo, se dan unas pinceladas que relacionan la epistemología de la evaluación con los pensadores que identifican cada una de sus etapas, las mismas se encuentran consolidadas como antecedentes referenciales, en: Escudero Escorza (2003), Gimeno Sacristán (1998), Mateo (2000), Mora Vargas (2004), Rosales López (2000), Shaw (2003) y Tenti Fanfani (2006), entre otros muchos estudiosos de la temática.

\section{Perspectivas y enfoques de la evaluación de los aprendizajes}

Para finales de siglo XX e inicio del siglo en curso, se evidencia la inclinación hacia el Post-racionalismo, la confluencia entre los paradigmas cuantitativo y cualitativo, y el paradigma informático, el cual tiene el beneficio de facilitar la posibilidad de acceso a la información tanto de profesores como de alumnos. Incluso estos, nacidos en la era de la informática, son más hábiles que sus profesores para desplazarse por la Web por medio de Internet, en las llamadas autopistas de la información, frase acuñada por el ex vicepresidente norteamericano Albert Al Gore en 1991, esto con el objetivo de definir una estructura de comunicación del futuro integrando todo tipo de medios y servicios a alta velocidad, tal como puede evidenciarse en Ríos Piñera (1996).

Ahora bien, esta realidad material para generar conocimiento, cultura y educación incrementa la posibilidad de que el alumno sea considerado el protagonista principal de su aprendizaje, con los cambios del proceso educativo que, como es lógico, incluye también la evaluación. Se puede afirmar que Sócrates, Quintiliano, Vives, Rousseau, Simón Rodríguez y tantos otros pedagogos no eran ajenos a la concepción pidocéntrica de la educación, pero carecían de los recursos instruccionales de los que se dispone hoy para operacionalizar el paidocentrismo.

Comenio (1971) plantea que paidocéntricamente se revisa, se piensa y repiensa todo el proceso educativo y también la evaluación, en la que, aunque no fuera más que por coherencia epistemológica, hay que darle participación al estudiante. Sobre el tema se ha producido considerable literatura pedagógica y también de evaluación de los aprendizajes, cuyo denominador común sería que no debe ser solo de aprendizajes, sino que la evaluación es parte integrante del aprendizaje, que ella debe ser aprendizaje, que va mucho más allá de la medición de saberes, que sirve para mucho más que para promover o retener alumnos en los grados, que es un insumo extraordinario e imprescindible para la ulterior planificación y mejoramiento. Así que cada quien va a hablar y escribir de la evaluación según su bagaje cultural y pedagógico.

Foucault (1981) en sus trabajos ha considerado el estudio de las relaciones entre saber y poder, referidas a la práctica de la aplicación del examen que permite el registro tangible para calificar, clasificar y castigar. El examen se convierte entonces en un procedimiento altamente ritualizado porque supone el despliegue del ejercicio de poder, disciplinando a los sujetos al volverlos visibles. Para el autor, el examen, rodeado de todas las técnicas documentales $\mathrm{y}$ formales, hace del individuo un caso que es por un lado objeto de conocimiento y, por otro, presa para el poder.

Fundamentalmente, el proceso de evaluación de los aprendizajes da cuenta de tres dimensiones esenciales: la expresión de un juicio de valor, la recolección de información para sustentar dicho juicio y el propósito o finalidad en la realización de los actos evaluativos. En este sentido, "evaluar es una práctica intencional que realiza un sujeto con el propósito de indagar, conocer y comprender a un objeto determinado (prácticas, sujetos, objetos), a partir de la formulación de un juicio de valor" 
(Mancovsky, 2007, p. 6). De tal manera que la evaluación no sólo es parte constitutiva del proceso EAAT, sino que se configura como una actividad necesaria que le otorga racionalidad a éste, en tanto suministra información valiosa sobre la actuación de cada uno de los actores sociales implicados en el proceso de aprendizaje, así como los instrumentos aplicados durante el mismo con los fines de controlar, reorientar o mejorar la acción didáctica. De allí que la evaluación es a su vez un proceso en sí mismo, en la que se consideran múltiples aristas y perspectivas que le otorgan una naturaleza compleja y multidimensional, algunas de las cuales se refieren a continuación.

- Perspectiva ontológica: se refiere a la visión que el docente posea con respecto al alumno, lo cual implica una determinada concepción de la realidad que éste debe evaluar y el campo que ella abarca. Esta perspectiva, según Rivera (2006), delimita los aprendizajes que son legítimamente considerados como dignos de ser evaluados, y comprende la percepción de la realidad, naturaleza de la realidad a evaluar, concepción, generación, metas de formación y desarrollo de los alumnos. Al respecto, Eisner (1998) refiere que más de lo que los educadores dicen, más de lo que ellos escriben en las guías curriculares, las prácticas de evaluación dicen lo que cuenta para profesores y estudiantes, qué intentan y qué rechazan, qué consideran importante los adultos.

- Perspectiva epistemológica: está vinculada a la visión que sobre la naturaleza y generación del conocimiento se posea, lo que a la vez sustenta la concepción curricular sobre la que descansa el proceso educativo. Tal como refiere Álvarez Méndez (2007) la evaluación, como proceso se encuentra estrechamente ligada a la naturaleza del conocimiento. "Una vez esclarecida ésta, la evaluación requiere ser fiel y mantener la coherencia epistemológica que le dé consistencia y credibilidad, manteniendo la cohesión entre la concepción y las realizaciones concretas" (p. 204). Se observa entonces que la lectura e interpretación del conocimiento positivista es coherente con una concepción curricular rígida, conductista, academicista, transmisionista de conocimientos y caracterizada por una evaluación medicionista, por objetivos o metas. Mientras que desde la mirada de la teoría crítica, se asume el currículo como un proyecto y proceso, dado que el pensamiento crítico es en sí mismo un proceso dinámico y social que exige juicio y deliberación, y que descansa en prácticas evaluativas formativas y de aprendizaje significativo.

- Perspectiva curricular: Concomitantemente con la perspectiva epistemológica, es necesario referir que tanto el aprendizaje como la evaluación están orientadas y dirigidas por el currículo, como idea global de principios y el marco de referencia que se concreta en prácticas específicas educativas y como proyecto social y político (Álvarez Méndez, 2007). Se asume entonces como la forma de organizar un conjunto de prácticas educativas articuladas con la visión del hombre y de la actuación de ese hombre en el mundo, tal como refiere Castro Rubilar: "las prácticas educativas y el currículo es un conjunto de ellas, no existen aparte de ciertas creencias sobre las personas y sobre la forma en que interactúan y deben hacerlo en el mundo" (2005, p. 19). En este sentido, la evaluación como parte de las actividades del proceso de enseñanza-aprendizaje está sustentada por la teoría que ilumina (corriente 
de la evaluación que se denomina "evaluación iluminativa") el currículo y por el telón de fondo de los intereses cognitivos de quienes participan en el proceso.

- Perspectiva pedagógica: está referida a la comprensión, regulación y mejora de la situación de enseñanzaaprendizaje, por lo cual se vincula con las teorías y modelos pedagógicos que sustentan el ser y hacer educativo en el aula. Es decir, el piso pedagógico en el que se desenvuelve el docente en cuanto al diseño curricular, al diseño instruccional, las estrategias y la conducción del proceso mismo, del proceso de aprendizaje, entre otras, de alguna manera da cuenta de las intencionalidades y desempeño de la labor evaluativa, de allí que esta perspectiva "se integra al proceso de enseñanza aprendizaje como una genuina evaluación continua dirigida a tomar decisiones de índole pedagógica y que verdaderamente justifica o le da sentido a la evaluación" (Díaz Barriga y Hernández Rojas, 2002, p. 354).

- Perspectiva técnica: el accionar operativo de la evaluación desde esta perspectiva depende exclusivamente de los docentes y se refiere a las herramientas, instrumentos o técnicas que se utilicen para recoger información valiosa para la toma de decisiones. En este sentido, de este accionar depende la elección de las estrategias, procedimientos $\mathrm{y}$ recursos que se utilice, además de la selección de quién o quiénes les darán uso; decidir si este es para medir la conducta observable en los alumnos, asumiendo la predicción y control absoluto del proceso y los resultados, o si más bien lo que se aspira es reflexionar y autorregular los aprendizajes de una manera contextualizada, flexible y controlada por los mismos estudiantes, situación en la que entonces se emplearán técnicas guiadas por la observación, registros anecdóticos, portafolios, autoevaluación y la coevaluación, entre otros. Igualmente, es posible encontrar la combinación de varios procedimientos técnicos como un recurso para enriquecer la obtención de la información sobre el desempeño del estudiante y del docente durante el proceso enseñanza-aprendizaje.

Perspectiva hermenéutica: en esta todos los participantes del proceso son sujetos activos; por lo tanto, la evaluación forma arte y parte del proceso enseñanza-aprendizaje desde la dinámica reflexiva de cada uno de sus actores. Los objetivos se transforman en hipótesis o en supuestos operativos y estratégicos y la evaluación se realiza con el propósito de mejorar la calidad del trabajo que se realiza y de influenciar en el mejoramiento de los sistemas educativos. Para ello es necesario que la evaluación sea entendida como un proceso que promueve el aprendizaje y no como un control externo realizado por el profesor sobre lo que hace el alumno y cómo lo hace. Es necesario asumir una reconducción permanente, sucesiva $\mathrm{y}$ comprensiva del proceso enseñanzaaprendizaje a la luz de las interpretaciones que generan las nuevas informaciones producto de la evaluación. A saber, las ideas de Bordas y Cabrera (2001):

la evaluación, incluida en el mismo acto de aprendizaje, comporta una mayor comprensión tanto por parte del profesor como del estudiante de los procesos que se están realizando así como el conocimiento de las razones de los errores y aciertos que se producen. El acto evaluativo desde esta perspectiva, más que un proceso para aprobar o certificar, se coloca como participante, como optimizador de los aprendizajes contribuyendo a proporcionar 
información relevante para introducir cambios y modificaciones para hacer mejor lo que se está haciendo... La evaluación no es demostrar sino perfeccionar y reflexionar (p. 33).

- Perspectiva holística: Cronbach (1963) en su concepción supone la focalización en las decisiones que se estiman serán tomadas tras la evaluación. Se realiza a lo largo de todo el proceso y no en el final. Hay un mayor énfasis en los componentes estructurales que en establecer comparaciones. El paradigma holístico de la evaluación debe entonces buscar y extraer descripciones a partir de observaciones de lo global y lo concreto. Además, abarca la concurrencia de múltiples tangibles que consolidan la evaluación, entre ellos, la auto-evaluación, coevaluación y evaluación externa, todo como un proceso articulado continuo. Este paradigma contempla a su vez la confrontación de la evaluación interna con la externa.

- Perspectiva metodológica: en esta se conjugan los tangibles e intangibles (lo que se ve y lo que no se ve, lo que se puede apreciar a simple vista y lo que subyace) del proceso de investigación aplicados a la evaluación. Es así como la planificación y diseño de los instrumentos requieren de superar las causas y los efectos para evidenciar en el momento de recoger los datos el logro de los objetivos planteados desde el inicio. Sin embargo y coincidiendo con Mateo (2000), por el hecho de que la evaluación constituye un universo en sí misma se convierte en una de las actividades de mayor trascendencia e influencia en la vida socio-educativa. La evaluación influye ya que ofrece información para guiar el camino o escoger otro mejor. En este sentido, el desarrollo resulta indispensable para mejorar e innovar los ámbitos educativos, entre los que destacan los programas y los actores involucrados. Desde esta perspectiva, la evaluación confiere condición científica al proceso educativo. Por ello, la evaluación de la cual no se deriven acciones perderá su credibilidad.

- Perspectiva ética: requiere de la conjunción de voluntades para el establecimiento de los valores, haciendo que los mismos se transformen en una forma práctica de vida que traspase las fronteras del aula y genere beneficios en la sociedad que demanda mejores ciudadanos. De allí que la evaluación va más allá de la cuestión didáctica, puesto que están implícitos los derechos adquiridos y concedidos a los alumnos que son acompañados por el docente en el singular camino del aprendizaje. La perspectiva ética comprende que "la evaluación es ante todo, una cuestión ética que implica, desde un principio, una intencionalidad del docente sobre el lugar y el reconocimiento del otro, el alumno" (Mancovsky, 2007, p. 6).

Como puede apreciarse en los párrafos anteriores y observarse en la figura 1, las perspectivas presentadas mantienen una relación de complementariedad, lo que indica el carácter complejo y multidimensional del proceso de la evaluación y, por ende, del proceso enseñanza-aprendizaje que se encuentra completo cuando se logra la asimilación y se opera una transformación en el ser humano. Es necesario entonces que los docentes generen un proceso de reflexión sobre el quehacer evaluativo en el aula, y de cómo el mismo se vincula con un estilo de pensamiento sobre su acción pedagógica que tiene que ver con la manera de concebir no sólo la educación, sino la participación de docentes, estudiantes, padres y representantes y actores comunitarios en dicha acción. 
Figura 1

Perspectivas de la práctica evaluativa en el aula

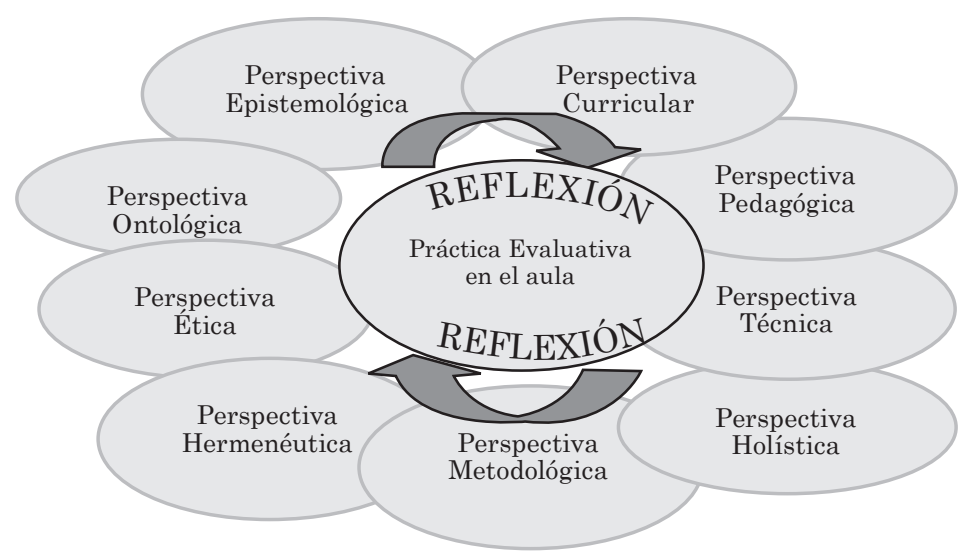

Fuente: Elaboración propia.

Se coincide con Díaz Barriga (2001, p. 4), quien plantea que "la evaluación educativa, como disciplina y como práctica, ha evolucionado significativamente en los últimos treinta años" a pesar de que el debate disciplinario de la evaluación no sea conocido o, peor aún, cuando los paradigmas se cambian sin evaluar su eficiencia o ineficiencia. En este punto se llega a olvidar que "la evaluación no es un apéndice, es parte de la enseñanza", tal como lo refiere Celman (1998, p. 6). En este orden de cosas, para los autores del presente artículo esta es arte y parte de un proceso complejo que involucra un ganar. Ganar sólo cuando la evaluación es utilizada para el mejoramiento continuo de la calidad del aprendizaje a la vez que forma parte significativa del proceso de gerencia del aula y produce cambios positivos, tanto tangibles como intangibles que influencian la realidad y una mejor calidad de vida. Cisterna Cabrera (2005) plantea que la evaluación en el ámbito educativo tiene varias funciones; sin embargo, la más congruente con el término educación es la de contribuir a mejorar los procesos educativos para que los educandos puedan alcanzar las metas de aprendizaje, ya sea que se expresen en términos tradicionales de objetivos, o como competencias cognitivas, procedimentales y actitudinales.

En esta conjunción de elementos, conviene hacer referencia a la Teoría Crítica que encierra en su esencia la necesidad de una evaluación transformadora que tiene sus bases en el legado dejado por Horkheimer (2000) de la Escuela de Frankfurt, que en la década de los treinta y cuarenta, junto con otros como Theodor Adorno, Herbert Marcuse y Erimm Fromm, por referir tan solo nombres de algunos de los más destacados exponentes de la teoría crítica, y Habermas (1981), representantes de la segunda generación de la teoría crítica centrada en la Teoría de la Acción Comunicativa, entre otros pensadores, partieron de la necesidad de una evaluación transformadora que, a su vez, fuera flexible e interdisciplinar, la que, complementada con lo planteado por Freire (1999), permitiera desarrollar una conciencia crítica para el reconocimiento de las conexiones existentes entre sus problemas y experiencias, en la cual la concienciación es el primer paso para una verdadera práctica evaluativa.

En este orden de ideas es necesario que los docentes permanentemente asuman 
la reflexión sobre el ser y hacer cotidiano de la práctica educativa en el desarrollo de los procesos de enseñanza-aprendizaje y sobre sus implicaciones en la asimilación y transformación, además de las perspectivas, concepción y dinámica evaluativa, sin olvidar que "del concepto de aprendizaje que proponen los diferentes paradigmas, se derivará la forma de entender y aplicar la evaluación" (Bernard, citado por Cisterna Cabrera, 2005, p. 10).

Las prácticas evaluativas en el aula generadas a partir de la reflexión crítica de los docentes han de ser producto de una concienzuda organización de la compleja cotidianidad del aprendizaje, y de cómo éste se constituye en un medio de calidad al servicio del alumno que aprende y también del mismo docente que aprende cada día del aprendizaje de sus alumnos. Es así como, más allá de la visión didáctica pedagógica del proceso de aprendizaje en el aula, el docente requiere asumir además una visión de planificación, diseño, dirección, motivación, comunicación, desarrollo de valores y toma de decisiones que redunden en la efectividad, eficacia, excelencia y calidad del proceso de aprendizaje en el aula y, por ende, de la evaluación; aspectos vinculados con la acción gerencial dentro del aula.

\section{El docente como gerente del aula}

Conviene iniciar este punto con la desagregación de lo que se entenderá por gerencia del aula. Al respecto se coincide con García (1999) cuando expresa que "la gerencia parte de un proceso que consiste en organizar adecuadamente las ideas e iniciativas y convertirlas en propósitos" ( $p$. 100 ) que requieren del potencial humano como centro de atención y como protagonista del cambio para así tener efectividad en la planificación, organización, dirección, evaluación y realimentación -PODER_2 de procesos que a su vez requieren que la gerencia se nutra de filosofías gerenciales actuales y en consonancia con la realidad.
Esto en conjunción con la misión, la visión y los valores que permitan a la gerencia ser eficaz, pertinente y eficiente, con especial referencia para incidir en la calidad de vida.

Esta definición sobre gerencia encaja perfectamente para ubicar al docente como gerente del aula, un gerente transformador, reflexivo, crítico y con visión de futuro para que se logre el proceso enseñanza-aprendizaje con la correspondiente asimilación y transformación. Además, avalando lo planteado por García y Pinto (2005), se puede afirmar que la calidad del proceso evaluativo, requiere de un docente capacitado para gerenciar el aula y con la capacidad de enfrentar los retos que se le presenten adecuándose a las exigencias del cambio en relación con la gran responsabilidad de ser el depositario de una alta profesionalización que legitime la relevancias de sus diagnósticos y sus prácticas evaluativas.

En este sentido, tal como se evidencia en el cuadro 1, en la ejecución de las acciones el docente tiene que asumir las funciones gerenciales de PODER que en definitiva le permitirán lograr cambios e influenciar para que otros reflexionen, aprueben $\mathrm{u}$ objeten, tomen decisiones, realicen negociaciones, entre otras actividades. Esto sin menosprecio del grado y de la edad de los participantes que pueden estar desde el maternal hasta la educación universitaria.

Se aprecia entonces una gerencia centrada en los elementos indicados como PODER, que debe ser compartido, en la cual el docente asume una postura como gerente de aula que ejercita el rol de planificador, rediseñador, implementador, evaluador, investigador y transformador del proceso EAAT, mediante el pensar y actuar sobre su práctica pedagógica, para lo cual requiere desarrollar una actitud proactiva, crítica y reflexiva frente a la enseñanza. De manera tal que se está preparando, ensayando, y experimentando continuamente para transformar el hacer educativo en espacios de compromiso que permitan a los estudiantes la construcción significativa y de calidad de 
los saberes y el desarrollo de competencias y habilidades significativas y pertinentes a sus necesidades y las del entorno.

A la luz de los planteamientos anteriores, se establece que la evaluación educativa desde y para una gerencia dinámica de calidad del aprendizaje en el trabajo del aula debe abarcar los elementos estructurales y potenciales del saber. En este sentido, se proponen lineamientos de referencia que, de ser considerados en la evaluación educativa, favorecerán e inclinaran la balanza en cada una de las fases del trabajo del aula, y, como resultado, se aspira a que la evolución se convierta en un proceso innovador con resultados de calidad y mejoramiento continuo.

\section{Práctica evaluativa de los aprendizajes en la gerencia participativa en el aula}

Tal como se ha evidenciado en el desarrollo del artículo, la evaluación de los aprendizajes en la práctica educativa representa uno de los problemas que a lo largo de la historia ha sido ampliamente discutido, ya que constituye parte integrante de un significativo y delicado proceso en la docencia, con especial incidencia en la calidad y gerencia del aula que, unida a la visión de futuro personal, profesional y de país, tendrá su impacto en la sociedad. Haciendo eco en las ideas de Freire (1999) cuando afirma que no hay nada que contradiga y perjudique más el emerger del pueblo que una educación que no lleve al educando a la experiencia del debate y del análisis de los problemas ni le propicie las condiciones para una verdadera participación. Se plantea entonces la necesidad de una construcción crítica de saberes y aprendizajes que sólo es posible en un ambiente democrático, en el cual las ideas no se dictan, por el contrario se intercambian, se discuten, se analizan, se reflexionan.

En el entendido de que la educación es una actividad social y socializadora, sus objetivos, metas y alcances son de naturaleza social; de allí que toda propuesta educativa tiene un proyecto social y cultural, así como un cierto ideal de cómo formar hombres educados que adquieran cultura y socialicen para su inserción y participación en la posible transformación de su sociedad. Por ello, la evaluación cumple su función social de acreditar o certificar ante la sociedad y comunidad cultural, si los estudiantes han conseguido determinados logros académicos o si poseen determinadas capacidades para acceder al campo laboral, desempeñar determinadas funciones sociales o asumir ciertos roles en la misma.

Como puede apreciarse, esta consideración implica la asunción del estudiante como centro de la acción evaluativa y por ende del proceso educativo, desde la perspectiva de su aprendizaje y desarrollo como ser humano y especialmente como ser social. Avalándose con Álvarez Méndez (2007), se establece que es importante reconocer al servicio de qué y de quién está el esfuerzo de quien enseña y de quien aprende, lo cual exigirá que el docente se sitúe frente al conocimiento y frente a su propia responsabilidad profesional; de allí que si la orientación es a favor de quien aprende, la acción tendrá una dirección y un interés muy distinto de la de quien, ajeno al devenir histórico, se empeña en mantener el statu quo.

Se asume entonces que el fin último de la acción evaluativa en el aula es para aprender, tal como refiere Álvarez Méndez (2007). La evaluación educativa tiene sentido y está plenamente justificada cuando actúa al servicio de quien aprende y asegura siempre y en todos los casos el correcto aprendizaje mediante las oportunas correcciones y las indicaciones pertinentes. Lo cual implica a su vez que, más allá de las cuestiones técnicas e instrumentistas, la evaluación es ante todo un proceso humanizado, pues coincidiendo con Freire (1999), sólo en la educación puede nacer la verdadera sociedad humana y ningún hombre vive al margen de ella. $\mathrm{Y}$ es que toda la tarea de educar solo es 
auténticamente humanista en la medida en que procure la integración del individuo a su realidad social, en la medida en que le pierda el miedo a la libertad, en la medida en que pueda crear en el estudiante un proceso de recreación, de búsqueda, de independencia y, a la vez, de solidaridad.

Por ello es necesario que desde el aula se generen procesos que promuevan el empoderamiento del estudiante conjuntamente con el docente para la planificación y desarrollo de los espacios de aprendizajes, y por ende de la evaluación. Se traslada entonces a una dinámica EAAT, donde lo verdaderamente importante no es la medición cuantitativa y exacta por parte del docente de lo que alcanza o no el estudiante de una forma unidireccional, sino que desde la conciencia y la corresponsabilidad individual o colectiva, los actores sociales involucrados realizan acciones de aprendizaje y de reflexión. Así lo refieren Bordas y Cabrera (2001) al plantear el empowerment como naturaleza de la evaluación:

A medida que el alumno aprende a autoevaluarse también aprende a saber identificar y expresar sus necesidades, a establecer objetivos y expectativas, a realizar un plan de acción para conseguirlos, a identificar recursos, a establecer pasos lógicos y necesarios para conseguir objetivos, a valorar los logros,... En esta perspectiva del empowerment, el agente de evaluación deja de ser exclusivamente el profesor. El alumno individualmente o en grupo, pasa a tener un papel fundamental, de tal manera que se le da un traspaso progresivo de la responsabilidad de la evaluación desde el profesor al alumnado. Para esto es necesario que el alumnado haga suyo los objetivos del aprendizaje, participe en el establecimiento de sistema y criterio de evaluación y, sobre todo, tenga capacidad para planificar la evaluación, utilizar autónomamente procedimientos evaluativos y seleccionar evidencias que muestran los logros conseguidos (p. 9).

En esta concepción de la evaluación, el docente asume un proceso de gestión y gerencia del aprendizaje muy diferente al tradicional, que podría complementarse con la tríada "eficacia, eficiencia y pertinencia”, propuesta por Contasti (1999). En este caso, el docente cede su poder y conjuntamente con los alumnos se desenvuelve en un escenario con sentido de mejoramiento continúo de la calidad de los aprendizajes. Por ello, en el presente trabajo se entiende la gerencia de los aprendizaje en el aula como todas las funciones colaborativas y participativas realizadas por los actores educativos (docentes, estudiantes, padres, representantes, directivos, entre otros) relativas a la adecuada gestión de los actos pedagógicos que permitan la configuración y mantenimiento de un ambiente en el aula propicio para el desarrollo la instrucción y el aprendizaje con criterios de calidad y excelencia. Se plantean acciones inherentes al proceso gerencial del aula que, para los autores del presente trabajo, corresponden a las siglas de: planificación, organización, dirección, evaluación y realimentación dentro de la gerencia de los aprendizajes en el aula, para lo cual se requiere considerar algunas premisas que se fundamentan en la acción participativa de los integrantes del proceso de enseñanza-aprendizaje-asimilación-transformación.

\section{Algunas premisas para la evaluación con acción participativa}

Con base en la revisión que antecede, relacionada con el tiempo en la historia de la evaluación de los aprendizajes, además de los apartes que dan luz sobre la necesidad de un escenario dinámico, participativo y crítico, se establecen algunas premisas para la evaluación con acción participativa en la gerencia del aula, la cual con visión de futuro debe incidir en el mejoramiento de la calidad de vida de sus actores, y muy especialmente de la sociedad. En este orden de ideas se hace necesario que se pueda:

- $\quad$ Establecer un escenario en el aula basadoenlacomunicación permanente entre los actores sociales (docentes, estudiantes, representantes, entre otros) para el mejoramiento continuo de la dirección y coordinación de esfuerzos. Para ello, es importante 
hacer esfuerzos no solo en los actos del habla como tales, sino también en los actos de la escucha, referidos a los intereses, motivaciones, inquietudes y aspiraciones de quienes están involucrados en el proceso de aprendizaje y por ende de la dinámica evaluativa.

- Asumir la participación activa de todos los actores en el proceso de gerencia dentro del aula, desde la planificación hasta la reflexión y realimentación del mismo que permita la oportuna toma decisiones durante el recorrido de aprendizaje.

- Configurar un sistema de evaluación de actuación, desempeño, alcances, metas y logros claros y bien definidos; que además sea fiable y permita la identificación del nivel de eficiencia con que realizan las actividades individuales y grupales.

- Configurar la evaluación operativa y estratégica en el marco de una gerencia de aula en la cual los elementos identificados como PODER permitan los ajustes y cambios necesarios. Esto como un todo organizado y sincronizado en el cual se valora de forma integral los pasos que garantizan la calidad de las acciones realizadas, con lo que se elimina la evaluación por resultado final, dando preferencia a la evaluación por procesos.

Estas premisas orientan a una práctica evaluativa que es parte integrante del proceso enseñanza-aprendizaje no como un fin terminal de este, por lo que está incorporada a una gerencia de aula abierta, flexible y participativa, que permite por un lado a los estudiantes autorregular sus procesos pedagógicos desde la perspectiva de las múltiples relaciones que se construyen o reconstruyen para dar paso a las transformaciones experimentadas en su aprendizaje, tal como refiere Blanco Gutiérrez (2004); por otro lado, obligan al docente a desenvolverse como un mediador crítico-reflexivo y potenciador-animador del aprendizaje de los estudiantes, por medio de una estrecha relación dialógica.

Efectivamente, uno de los aspectos claves de un buen proceso evaluativo en el aula es que se ofrezca información de retorno que le permita al estudiante reconocer en su actuación los logros y limitaciones, así como la toma de conciencia sobre los compromisos de mejora; proceso en el cual debe participar el propio docente al ofrecer sus sugerencias $\mathrm{u}$ orientaciones sobre el hilo a seguir o las oportunidades de recuperación. Igualmente, el docente debe informar en forma clara sobre los criterios utilizados o los acordados antes, durante y luego de la aplicación de cualquier estrategia de evaluación. Al respecto, Zabalza (2007) refiere que:

Tanto más formativa es y tanto mayor formativo tiene una evaluación cuanto mayor es su nivel informativo. Esa información deberá referirse tanto a los criterios que se utilizarán en la valoración (información previa que puede figurar ya en el programa pero que habría que recordar antes de la evaluación) como a las características observadas en el trabajo evaluado (feeback posterior) (p. 204).

Sin embargo, no basta con "informar". La concepción de la práctica evaluativa que se ha esbozado hasta ahora en el presente artículo requiere una acción de diálogo entre el docente y el estudiante desde una perspectiva metacomunicativa, es decir, comunicarse sobre cómo se está desarrollando la comunicación. De allí que la comunicación se constituye en el contenido mismo de la comunicación, lo cual resulta fundamental para el asentamiento de una dinámica interactiva válida (Zabalza, 2007, p. 198). Para ello, es necesario alejarse de la actitud rígida y autoritaria del docente y generar un ambiente más distendido que conlleve a un acercamiento entre el docente y el alumno, a fin de establecer conversaciones informales y sencillas sobre lo que les gusta o les disgusta de las clases, la aclaración de malentendidos, el definimiento de reajustes o simplemente el intercambio de las vivencias más resaltantes logradas en el curso. 
Esta nueva actitud del docente no tiene que significar la pérdida de la autoridad o ceder siempre sobre su particular visión de la realidad educativa, sino más bien estar dispuesto a reconocer en el estudiante un co-actor y co-partícipe, por demás principal interesado, en la ruta de construcción y apropiación de saberes. Pérez Luna y Sánchez Carreño (2004) plantean que desde esta perspectiva la evaluación se convierte en un elemento que favorece la transformación promoviendo en el proceso cambios en las concepciones, creencias, valores e interpretaciones y facilitando el ejercicio democrático del poder y la autoridad en el contexto escolar.

Se plantea entonces la importancia que tiene la planificación, organización, dirección, evaluación y realimentación del proceso, lo que ha sido entendido como PODER y que cumple con la característica de ser participativo en la dinámica de los procesos inherentes en la gerencia del aula, donde la práctica evaluativa de los aprendizajes se constituye en el elemento dinamizador de una acción consensuada, crítica y reflexiva que sustenta una pedagogía transformadora. Para ilustrar esto, ver el cuadro 1 que contiene las fases y acciones estratégicas que pueden configurar un escenario de PODER de la gerencia participativa y sus implicaciones en la práctica evaluativa en el aula.

En este punto se quiere dejar establecido que el proceso de evaluación es cíclico y dependiente de las individualidades de los actores involucrados. En este sentido el proceso enseñanza-aprendizaje requiere para ser completo de la asimilación y la transformación, a las que Kolb (1974) presenta como dos grandes dimensiones de la actividad, en la cual la asimilación se desarrolla en los extremos de los abstracto y lo concreto, mientras que la transformación tiene lugar en la actividad y en la reflexión.

Al llegar a este punto de la reflexión, se procede a la inclusión del cuadro 2 (ver página 29), en el que se teoriza cómo debe ser la evaluación educativa, esto teniendo presente que la capacidad especulativa y de formulación de teorías de la Evaluación siempre ha sido muy superior a las realizaciones prácticas, los docentes de todos los niveles y modalidades del sistema educativo de cualquier país deberían aplicar sin inconvenientes los aspectos teóricos de la evaluación educacional expuestos y comentados.

Obviamente, las universidades y demás instituciones del nivel superior, sobre todo las escuelas y programas de Educación, tienen un compromiso mayor y una responsabilidad ineludible en los procesos de cambio del paradigma educacional didáctico-evaluativo. Tal como lo expresan García y Pinto (2003), es una demanda de la sociedad del entorno y un reto al que se enfrentan para cumplir desde ya con la sociedad del futuro. Pero no es fácil asumir el reto en un mundo cada vez más globalizado y globalizante, donde cada día más, por obra de los medios de comunicación y divulgación del conocimiento como son las tecnologías de la información y comunicación (TICs), se facilita el proceso enseñanza-aprendizaje-asimilación-transformación para unos, mientras que para otros se hace cada vez más inalcanzable.

Coincidiendo con García y Pinto (2004, 2005), se hace notar que no ha sido ni será fácil desaprender una forma de enseñar y evaluar, la del aula real o presencial, para empezar a aprender a enseñar y evaluar en el aula virtual, lo cual es todo un proceso de re-alfabetización, mucho más difícil que el de la alfabetización, en el que las tecnologías de la información y comunicación (TICs) son un recurso sumamente útil en todo el proceso enseñanza-aprendizaje-asimilación-transformación, incluida la evaluación. Se destaca que en muchos de los casos esta actualización depende más de la actitud de cada profesor que de la disponibilidad de recursos por parte de la institución. 


\section{Cuadro 1}

Hacia una gerencia participativa en la práctica evaluativa

\begin{tabular}{|c|c|}
\hline Fases & Acciones \\
\hline Planificación & $\begin{array}{l}\text { Establecimiento de metas y objetivos tanto del proceso de enseñanza aprendizaje, como de la eva- } \\
\text { luación propiamente dicha, además de los pasos y los medios para conseguir dichos objetivos. } \\
\text { Determinación de propósitos claros y la definición de la racionalidad técnica que acompaña } \\
\text { a dichos propósitos por medio de encuentros conversacionales entre los actores educativos } \\
\text { interesados a fin de precisar las expectativas, intereses y motivaciones sobre el proceso de } \\
\text { EAAT que se desea emprender, con el fin de establecer las metas e intenciones. } \\
\text { Información permanente de todo el proceso para dar el seguimiento requerido y realizar los } \\
\text { ajustes correspondientes. }\end{array}$ \\
\hline Orga & $\begin{array}{l}\text { Materialización de las ideas para cumplir la planificación establecida. Igualmente, es im- } \\
\text { portante definir los niveles y momentos en los que cada actor social va a participar y cómo } \\
\text { va a participar tanto en la planificación como en el desarrollo del aprendizaje, } \\
\text { Definición de las condiciones, el entorno y los espacios físicos, materiales y técnicos en los } \\
\text { que se desarrollarán las actividades. } \\
\text { Adecuación de los recursos, medios, estrategias, tiempo y actuaciones durante todo el proceso. }\end{array}$ \\
\hline Dire & $\begin{array}{l}\text { Implementación de los proyectos, actividades y estrategias organizadas para el logro del } \\
\text { proceso. Dar lugar al desarrollo de las funciones de promoción, negociación, asistencia téc- } \\
\text { nica, velocidad de respuesta individual y grupal. } \\
\text { Establecimiento y desarrollo de estrategias de supervisión, observación y monitoreo del progreso } \\
\text { de las actividades significativas de aprendizaje y evaluación de estas, previamente planificadas. }\end{array}$ \\
\hline Evaluación & $\begin{array}{l}\text { Es una actividad permanente, inmersa en cada una de las fases, que permite la vigilancia y con- } \\
\text { trol de cada una de las fases del proceso, e implica la observación permanente de las actuaciones de } \\
\text { los implicados, así como de los recursos, técnicas, espacios, tecnologías y materiales empleados. } \\
\text { Establecimiento de espacios y momentos de reflexión dialógica entre cada uno de los actores } \\
\text { del aprendizaje y de la evaluación, a fin de intercambiar ideas sobre la actuación de cada } \\
\text { uno, y los logros alcanzados hasta el momento. Los estudiantes tienen oportunidades de } \\
\text { revisar los productos evaluativos y el nivel de efectividad de los mismos. } \\
\text { Diseño de técnicas de registro individual y colectivo para sistematizar de manera conscien- } \\
\text { te el cuándo, dónde y cómo de las acciones acordadas sobre los actos de aprendizaje, y ello } \\
\text { incluye las mismas prácticas evaluativas. }\end{array}$ \\
\hline Realimentación & $\begin{array}{l}\text { Determinación de aciertos y desaciertos en el proceso enseñanza-aprendizaje-asimilación-trans- } \\
\text { formación para una adecuada toma de decisiones respecto a las nuevas rutas del aprendizaje. } \\
\text { Definición de espacios conversacionales para establecer acciones a seguir que permitan el } \\
\text { mejoramiento continuo de los procesos, en términos de ajuste de objetivos y metas, técnicas } \\
\text { y recursos empleadas, y nuevas actuaciones de los interesados. } \\
\text { Incorporación de sugerencias y aportaciones para el mejoramiento o modificación de las } \\
\text { rutas o estrategias empleadas hasta el momento en la evaluación. }\end{array}$ \\
\hline
\end{tabular}

Fuente: Elaboración propia.

Se requiere que lo presentado en el cuadro 2 pueda ser una realidad ya que solo así la evaluación será verdaderamente entendida desde una óptica democrática y transformadora del proceso enseñanza. Se debe tomar en cuenta las diferentes formas de participar en ella, en las que han de utilizarse todas aquellas formas y 
Cuadro 2

Práctica evaluativa desde la gerencia del aula

\begin{tabular}{|c|c|c|}
\hline \multicolumn{3}{|c|}{ Práctica evaluativa } \\
\hline & Debe ser & Facilita \\
\hline 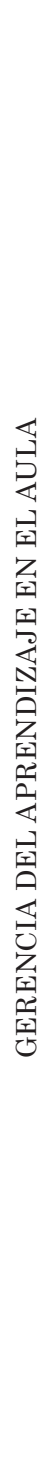 & $\begin{array}{l}\text { Centrada en el aprender a aprender. } \\
\text { Interactiva para que docentes y estudiantes } \\
\text { compartan el liderazgo y la responsabilidad en } \\
\text { lo que hemos denominado PODER. } \\
\text { Coherente entre la planificación y actuación } \\
\text { didáctica del docente con la práctica eva- } \\
\text { luativa. } \\
\text { Ética, como norma de actuación de todos los } \\
\text { involucrados y centrada en valores. } \\
\text { Relevante y con significado para el evaluador } \\
\text { y el evaluado. } \\
\text { Gestionada dentro de los criterios de calidad y } \\
\text { mejoramiento continuo para el enriquecimiento } \\
\text { de los actores y participantes. } \\
\text { Influyente en todos los aspectos del desarrollo } \\
\text { personal del evaluado con incidencia en el ámbi- } \\
\text { to familiar y social. } \\
\text { Significativa para la auto corrección y auto } \\
\text { mejoramiento, con la autorregulación por parte } \\
\text { del docente y del alumno. } \\
\text { Abierta a la consideración de la complementa- } \\
\text { riedad tanto del paradigma cualitativo como } \\
\text { del paradigma cuantitativo, como vía para la } \\
\text { validez y fiabilidad de los juicios de valor sobre } \\
\text { las actuaciones observadas. } \\
\text { Promotora del trabajo colaborativo, y las acti- } \\
\text { vidades destinadas a afianzar conocimientos y } \\
\text { competencias, así como a vincular las experien- } \\
\text { cias previas con las nuevos saberes y habilida- } \\
\text { des por aprender. } \\
\text { Abierta para priorizar los espacios de inter- } \\
\text { cambio comunicativo y negociador entre los } \\
\text { involucrados: docentes, alumnos, padres, repre- } \\
\text { sentantes, entre otros. } \\
\text { teomo recurso para la evaluación. }\end{array}$ & $\begin{array}{l}\text { La adquisición y construcción del conocimiento, } \\
\text { pero también la comprensión de lo que da sentido } \\
\text { al conocimiento. } \\
\text { La creación de oportunidades y posibilidades } \\
\text { para el seguimiento, valoración y evaluación de } \\
\text { los resultados obtenidos durante el proceso. } \\
\text { La innovación y creatividad para el establec- } \\
\text { imiento de relaciones significativas entre distin- } \\
\text { tos saberes en una realidad cada vez más multi- } \\
\text { cultural. } \\
\text { Situaciones en las que la persona pueda conoc- } \\
\text { erse a sí misma y ejercitar su discernimiento pri- } \\
\text { mordialmente para el dominio sobre sí misma. } \\
\text { La toma de decisiones y el desarrollo de actua- } \\
\text { ciones voluntarias y libres dentro de los princip- } \\
\text { ios éticos y morales. } \\
\text { Posibilidades de elección entre distintas alternati- } \\
\text { vas y obrar según su propio razonamiento. } \\
\text { Que la persona que aprende también pueda ser } \\
\text { crítica y evalúe, discrimine, valore, opine, anal- } \\
\text { ice, describa, critique, razone, decida, funda- } \\
\text { mente, seleccione y construya, entre otros. } \\
\text { La construcción de un ambiente de aprendizaje } \\
\text { donde los involucrados se sienten motivados e } \\
\text { interesados, y especialmente felices de las expe- } \\
\text { riencias experimentadas en forma individual y } \\
\text { colectiva. } \\
\text { La exploración, al análisis, la crítica, la creación y } \\
\text { descubrimiento de ideas para convertir la evalu- } \\
\text { ación en un proceso de diagnóstico, estimulación } \\
\text { y comunicación (Pérez y Sánchez, } 2004 \text { ). } \\
\text { La Configuración de espacios de aprendizaje que } \\
\text { permite el ejercicio democrático de los actores } \\
\text { educativos en la gerencia del proceso. EAAT. }\end{array}$ \\
\hline
\end{tabular}

Fuente: Elaboración propia.

modalidades evaluativas que estimulen $\mathrm{y}$ propicien un ambiente participativo $\mathrm{y}$ coparticipativo, talescomolaautoevaluación. Estas deben, por una parte, permitirle al alumno enfrentarse de manera crítica a su proceso de aprendizaje y, a la vez, fortalecer su autonomía y autoestima; por otra parte, deben permitirle al docente que pueda 
reorientar sus estrategias y analizar su papel como facilitador de los aprendizajes.

Por ejemplo, con la coevaluación los alumnos ponen en práctica la convivencia del grupo y expresan opiniones basadas en la reflexión, y el docente destaca los avances, logros, dificultades y carencias del grupo. Por su parte, la heteroevaluación, como proceso de valoración recíproca permite discutir los progresos e interferencias ocurridas durante el aprendizaje, así como revisar los métodos, técnicas y estrategias de enseñanza utilizados durante toda la acción educativa. Como complemento, se considera importante cerrar este punto con una observación de Álvarez Méndez (2007) sobre la persona que aprende:

Desde las concepciones alternativas, y mas [sic] a tono con los nuevos enfoques curriculares, orientados por la racionalidad práctica y crítica, quien aprende tiene mucho que decir de lo que aprende y de la forma en que lo hace, sin que su palabra gravite constantemente el peso del ojo evaluador que todo lo ve y todo lo juzga. Por este camino podremos llegar a descubrir la calidad de lo aprendido y la calidad del modo en que aprende el alumno, las dificultades que encuentra en la naturaleza de las mismas, la profundidad y consistencia de lo aprendido y la capacidad generadora para nuevos aprendizajes de aquello que hoy damos por aprendido con solo haberlo oído y haberlo evocado en un escrito. Esta es la evaluación que mira al valor agregado de la enseñanza como indicador válido de la calidad de la educación (p. 35).

\section{Reflexione finales}

No cabe duda que la evaluación es parte integrante del proceso enseñanzaaprendizajequeseconsideracompletocuando se logra la asimilación y transformación en positivo y como tal desborda el mero hecho docente, pues de la adecuada asimilación y transformación se derivan repercusiones que inciden directamente en el destino educativo y personal del estudiante. Por ello, y avalado con lo planteado por Zabalza (2007), la problemática de la evaluación es realmente compleja y adquiere connotaciones que van mucho más allá de la buena voluntad o la opinión personal de cada docente, ya que se está afectando derechos importantes de los estudiantes.

Por mucho tiempo la evaluación ha estado ligada al ejercicio del poder y de la autoridad, ha supuesto la existencia de alguien que sabe y alguien que no sabe, por lo que se le ha asumido tradicionalmente como el instrumento fundamental para clasificar y someter a los alumnos y como la vía que el docente utiliza para expresar su poder. Por ello, no es raro encontrar que existen algunos docentes que irrumpen contra los derechos de los alumnos y estos lo aceptan por considerar que el docente es la autoridad, entendida en términos de manejo de conocimiento y del ejercicio del poder que ha sido delegado en ellos por él Estado para educar a la sociedad (Pérez Luna y Sánchez Carreño, 2004).

La constatación de los resultados y de las consecuencias negativas que esta práctica evaluativa ha ocasionado en la calidad del los procesos de enseñanza-aprendizajeasimilación-transformación ha conducido a plantear aproximaciones sobre la evaluación que promuevan el aprendizaje centrado en la participación democrática y co-responsable del estudiante y en la posición mediadora del docente. Estas aproximaciones se alejan de la postura esencialmente medicionista y objetivista de la evaluación, concebida casi siempre como un proceso que complementa la acción didáctica del aprendizaje.

Se han revisado en el presente artículo diversas perspectivas y enfoques que están implícitos en la práctica evaluativa y cómo cada una de ellas puede ser asumida de manera implícita y explícita por el docente desde cada uno de sus quehaceres y actos educativos dentro y fuera del aula (pedagógicos, administrativos, comunitarios, entre otros). Por ello, es necesario dejar claro que no se pueden emprender cambios en la educación solo desde la defensa y el discurso de nuevas corrientes pedagógicas constructivistas, sino que es necesario que los actos educativos sean también coherentes con una nueva visión y vinculación entre el aprender 
a ser, hacer, conocer y convivir educativo del docente y del alumno en el aula.

Tal como lo expresan Rivera y Piñero (2006), hay una necesidad de asumir un proceso de evaluación educativa que desde el enfoque cualitativo genere "un espacio para la reflexión, comprensión y valoración de los avances, intereses, aspiraciones, consideraciones e interpretaciones de quienes participan en la acción educativa” (p. 30), ante lo cual los autores expresan que no es tarea fácil debido a la complejidad que el hecho educativo encierra. Se requiere entonces de la conjunción de voluntades y la modificación de un conjunto de hábitos organizativos no dependientes exclusivamente de lo asumido por los hábitos o la costumbre en el tiempo, de ahí la importancia de la orientación para la evaluación con el enfoque interpretativo y crítico, el cual permite la interpretación y comprensión de la realidad, que, compleja y cambiante, se encuentra determinada por las relaciones e interrelaciones humanas.

Desde esta perspectiva, se ve la evaluación como un proceso dinámico, complejo, participativo, reflexivo y dialógico centrado en el aprendizaje formativo, que a su vez requiere la garantía del logro EAAT. Al respecto, Álvarez Méndez (2008) expresa: "Sólo cuando aseguremos el aprendizaje podremos asegurar la evaluación, la buena evaluación que forma, convertida ella misma en medio de aprendizaje y en expresión de saberes. Sólo entonces podemos hablar con propiedad de evaluación formativa" ( $p$. 12). Por ello, se parte de la idea de una concepción democratizadora de los procesos de gerencia del aprendizaje en virtud de que la evaluación se sustenta en principios de negociación, transparencia de la información, motivación, participación y corresponsabilidad entre el docente y el estudiante.

Esta consideración sustenta la configuración de un escenario que posibilite una gerencia participativa con las implicaciones que conlleva en la práctica evaluativa en el aula, cuyo eje vertebral está en la comunicación y la reflexión crítica de y entre cada uno de los actores educativos. Esto sin olvidar lo planteado por Stake (2006):
En toda reflexión que hagamos, contaremos con la ayuda del pensamiento basado en criterios. Cada vez que evaluemos, necesitaremos tanto una evaluación basada en estándares como una evaluación comprensiva. Juntas, rara vez se suman la una a la otra, pero gracias a las visiones separadas que nos proporcionan, podemos movernos con una mayor sensibilidad, pensar con mayor profundidad, informar con mayor cautela y comprometernos más a fondo con la tarea de representar la calidad (p. 382).

Una aproximación holística a la evaluación transformadora requiere maximizar la eficiencia y la eficacia del rendimiento para minimizar la insatisfacción que un proceso evaluativo no bien llevado puede ocasionar. En este sentido, destaca la importancia de la existencia de un lenguaje común entre el evaluador y el evaluado, tal como lo refiere House (2000), quien plantea que en el principio de la evaluación el evaluador debe basarse en los acuerdos con los destinatarios. Estos acuerdos pueden ser tanto implícitos como explícitos, de forma que pueda darse una comprensión compartida de la situación.

Coincidiendo con Mateo (2000), la evaluación se encuentra en la base de todos los cuestionamientos de gestión de la calidad educativa. Esta orientación agrega elementos sociales, educativos, culturales, religiosos y políticos de gran relevancia que la hacen cada vez más compleja, por lo que se requiere la reflexión constante y un trabajo innovador, participativo y colaborativo aunado a la práctica cotidiana de la gerencia por medio de la calidad de lo entendido por PODER, de forma que implique un proceso cultural y técnico que se practique ya que no habría recetas preestablecidas, simplemente elementos referenciales de apoyo para resolver los problemas evaluativos desde diferentes ópticas en distintos escenarios del quehacer educativo de los aprendizajes en el aula.

Desde esta perspectiva, la evaluación debe ser concebida como un proceso participativo, continuado, holístico, científico, formador, flexible, individualizado, cooperativo, consensuado, ético, proactivo, dialógico 
y reflexivo, en el que la persona que aprende toma conciencia de sí mismo y la responsabilidad de sus metas de aprendizaje, y el que enseña se constituye en un guía y mediador que orienta al logro de unos objetivos culturales y formativos.

\section{Notas}

$1 \quad$ Al referirse al proceso enseñanza, aprendizaje, asimilación y transformación; será indicado en el texto, como EAAT. Esto partiendo de que el proceso enseñanza-aprendizaje, se complementa con la asimilación y la transformación. En este sentido, conviene destacar que:

Enseñanza es la comunicación de conocimientos, habilidades, ideas y experiencias. Un sistema o método que sirve para enseñar y aprender. Es un conjunto de conocimientos, medios, personas y actividades que hacen posible la educación.

Aprendizaje es un cambio relativamente permanente en el comportamiento que refleja una adquisición de conocimientos o habilidades por medio de la experiencia y que puede incluir el estudio, la observación y la práctica.

Asimilación se refiere a la adquisición por la práctica de una conducta duradera. Comprender lo que se aprende e incorporarlo a los conocimientos previos. Es hacer como propio lo aprendido.

Transformación es hacer cambiar de forma de sentir, pensar o actuar (Real Academia Española, 2001).

$2 \quad$ Al referir el proceso gerencial que implica Planificación, Organización, Dirección, Evaluación y Realimentación; se utilizarán las siglas PODER.

\section{Referencias bibliográficas}

Alkin, M. C. (1973). Evaluation theory development [Desarrollo de la teoría de la evaluación]. En B. R. Worthen y J. R. Sanders (Comps.), Educational evaluation: Theory and practice [La evaluacióneducativa: Teoríaypráctica]. Worthington, Ohio: Charles A. Jones
Pub. Co. [Reimpresión de Evaluation Comment, (1969), 2(1), 2-7].

Álvarez Méndez, J. M. (2007). Evaluación: Entre la simplificación técnica y la práctica crítica. Revista Novedades Educativas, 18(195), 19-28.

Álvarez Méndez, J. M. (2008). Evaluar para conocer. Examinar para excluir (3era. ed.). España: Ediciones Morata.

Bacon, F. (2004). Novum organum [Indicaciones relativas a la interpretación de la naturaleza]. Buenos Aires, Argentina: Editorial Losada, S.A

Blanco Gutiérrez, O. (2004). Tendencias en la evaluación de los aprendizajes. Revista de Teoría y Didáctica de las Ciencias sociales, 9, 111-130.

Bloom, B. S., Hastings, J. T., y Madaus, G. F. (1975). Evaluación de los aprendizajes. Buenos Aires, Argentina: Editorial Troquel.

Bordas, M. I., y Cabrera, F. A. (2001). Estrategias de evaluación centradas en procesos. Revista Española de Pedagogía, 59(218), 25-48. Consultado el 25 de marzo de 2008 de: http://www.revistadepedagogia. org/rep.htm

Canterbury, A. (1998). Proslogion. Colección Clásicos del Pensamiento. España: Ediciones Tecnos.

Castro Rubilar, F. (2005). Gestión curricular: Una nueva mirada sobre el currículum y la institución educativa. Revista Horizontes Educacionales, 10, 13-25. Consultado el 20 de febrero del 2008, de: http://helios.dci.ubiobio. cl/revistahorizontes/Revista/files/ revistas/n10_2005.pdf 
Celman, S. (1998). ¿Es posible mejorar la evaluación y transformarla en herramienta de conocimiento? En A. Camilloni, S. Celman, E. Litwin y M. C. Palou, La evaluación de los aprendizajes en el debate didáctico contemporáneo (pp. 35-66). Buenos Aires, Argentina: Ed. Paidós.

Cisterna Cabrera, F. (2005). Evaluación, constructivismo y metacognición. Aproximaciones teórico-prácticas. Revista Horizontes Educacionales, 10, 27-35. Consultado el 20 de febrero del 2008, de: http://helios.dci.ubiobio. cl/revistahorizontes/ Revista/files/ revistas/n10_2005.pdf

Comenio, J. A. (1971). Didáctica magna. Madrid: Editorial Reus, S. A.

Contasti, M. (1999). Génesis e historia de la tríada de evaluación: Eficacia, eficiencia y pertinencia. Educación y Ciencias Humanas, 7(12), 33-46.

Cronbach, L. (1963). Designing evaluations of educational and social programs [Diseño de evaluaciones de los programas educativos y sociales]. Chicago: Jossey-Bass.

De Mattos, L. A. (1974). Compendio de didáctica general (2da. ed. revisada y ampliada). Argentina: Editorial Kapeluz.

Díaz Barriga, Á. (2001). El examen, evaluación o masificación de la examinación. Perfiles Educativos, 23(91), 2-6.

Díaz Barriga, A., y Hernández Rojas, G. (2002). Estrategias docentes para un aprendizaje significativo: Una interpretación constructivista (2da. ed.). México: McGraw-Hill.
Eisner, E. W. (1998). El ojo ilustrado. Indagación cualitativa y mejora de la práctica educativa. Barcelona, Paidós.

Escudero Escorza, T. (2003). Desde los test hasta la investigación evaluativo actual. Un siglo, el XX, de intensivo desarrollo de la evaluación en educación. Revista Electrónica de Investigación y Evaluación Educativa, 9(1), 11-43.Consultado el 17 agosto 2008 de: http://www.uv.es/ RELIEVE/v9n1/RELIEVEv9n1_1. pdf

Fernández Sierra, J. M. (1994) Evaluación y currículum: Perspectivas curriculares y enfoques en su evaluación. En J. F. Angulo y N. Blanco (Coords.), Teoría y desarrollo del curriculum (pp. 295-310). Málaga: Aljibe.

Foucault, M. (1981). Vigilar y castigar: Nacimiento de la prisión. España: Editorial Siglo XXI.

Freire, P. (1999). La educación como práctica de la libertad (49a. ed.). España: Ediciones Siglo XXI.

García, B. C. (1999). Educación universitaria, investigación y gerencia en la calidad de vida. Ciencias de Gobierno, 5, 87-102.

García, B., y Pinto, T. (2003) Educación universitaria, demanda del entorno y retos de la sociedad del futuro. Revista Cubana de Educación Superior, 23(2), 14-31.

García, B., y Pinto, T. (2004) Encuentros $\mathrm{y}$ desencuentros entre las funciones del profesor universitario con las nuevas tecnologías de la información y comunicación. Revista Encuentro Educacional, 11(3), 424-447. 
García, B., y Pinto, T. (2005). Las nuevas tecnologías de la información y la comunicación y las funciones del profesor universitario. Revista Encuentro Educacional, 12(3), 415441.

Gimeno Sacristán, J. (1998). La evaluación en la enseñanza. En J. Gimeno Sacristán y Á. I. Pérez Gómez, Comprender y transformar la enseñanza (pp. 334-397). España: Editorial Morata.

Guba, E. G., y Lincoln, Y. S. (1989) Fourth generation evaluation [Evaluación de cuarta generación]. Newbury Park, California: Sage Publications, Inc.

Habermas, J. (1981). Teoría de la acción comunicativa. Tomos I y II. Madrid: Ediciones Taurus.

Horkheimer, M. (2000). Teoría tradicional y teoría crítica. Barcelona, España: Ediciones Paidós Ibérica.

House, E. R. (2000). Evaluación, ética y poder (3era. ed.). Madrid, España: Ediciones Morata.

Kemmis, S. (1998). Teoría crítica de la enseñanza. España: Ediciones Morata.

Kolb, D. (1974). On management and the learning process [Sobre la gestión y el proceso de aprendizaje]. En D. A. Kolb, I. Rubin, y J. McIntyre (Eds.), Organisational psychology: A book of readings [La psicología organizacional: Un libro de lecturas] (pp. 239252). New Jersey: Prentice Hall.

Lafourcade, P. D. (1973). Evaluación de los aprendizajes. Buenos Aires: Editorial Kapelusz, S. A.

MacDonald, B. (1989). La evaluación y el control de la educación. En J. Gimeno
Sacristán y A. Pérez Gómez (Eds.), La enseñanza: Su teoría y su práctica (3era. ed.) (pp. 467-478). Madrid: Akal.

Mancovsky, V. (2007). Hacia una concepción ética de las prácticas evaluativas. Revista Novedades Educativas, 18(195), 27-46.

Mateo, J. A. (2000). La evaluación educativa. Su práctica y otras metáforas. Cuadernos de Educación. Barcelona: Editorial Horsori.

Mora Vargas, A. I. (2004). La evaluación educativa. Concepto, períodos y modelos. Actualidades Investigativas en Educación, 4(2), 1-28. Consultado el 2 de febrero de 2008, de: http://revista.inie.ucr.ac.cr/articulos/2-2004/ periodos.

Parlett, M., y Hamilton, D. (1989). La evaluación como iluminación. En J. Gimeno Sacristán y A. Pérez Gómez (Eds.), La enseñanza: Su teoría y su práctica (pp. 450-466). Madrid: Akal.

Pérez Luna, E., y Sánchez Carreño, J. (2004). Evaluación, conocimiento y poder. Revista Encuentro Educacional, 11(2), 218-228.

Posner, G. J. (1998). Análisis del currículo (2da. ed.). Bogotá, Colombia: McGraw-Hill.

Ratio Studiorum Oficial. (1599). Consultado el 12 de diciembre 2008, de: http:// eduignaciana.tripod.com/docum/ ratio.pdf

Real Academia Española. (2001). Diccionario de la Real Academia Española (22a. ed.). Consultado el 24 de octubre del 2008, de: http:// buscon.rae.es/draeI 
Ríos Piñera, J. J. (1996). La sociedad de la información: Una revolución silenciosa. Consultado el 17 de agosto del 2008, de: http://www.carm.es/chac/ articulos.htm\#1

Rivera, M. E. (2006). Modelo interpretativo de los docentes frente a la evaluación del aprendizaje. Revista EDUCARE, 10(1), 13-34.

Rivera, M. E., y Piñero, M. L. (2006). La generación emergente en la evaluación de los aprendizajes: Concepciones y modelos. Laurus, 12(22), 26-48.

Rosales López, C. (2000). Evaluar es reflexionar sobre la enseñanza (3era. ed.). España: Ediciones Narcea.

Rowntree, D. (1977). Assessing students. How shall we know them? [La evaluación de los estudiantes. ¿Cómo los conocemos?]. Gran Bretaña: RoutledgeFalmer, Taylor \& Francis Group. Consultado el 08 de diciembre del 2008, de: http://www.dem.fmed. uc.pt/Bibliografia/Livros_Educacao_ Medica/Livro06.pdf

Salmo 139. (1995). En VV.AA., y Valera Reina (Eds.), Santa Biblia. Madrid, España: Ediciones Sociedad Bíblica.

Scriven, M. (1974). Evaluation perspectives and procedures [Perspectivas y procedimientos de evaluación]. En W. J. Popham (Ed.) Evaluation in education [Evaluación y educación] (pp. 3-93). Berkeley, California: McCutchan Publishing.

Shaw, I. F. (2003). La evaluación cualitativa. Introducción a los métodos cualitativos. Barcelona, España: Ediciones Paidós Ibérica, S.A.

Shinkfield, J., y Stufflebeam, D. (1995). Teacher evaluation. Guide to effecti- ve practice [Evaluación del profesor. Guía para una práctica efectiva]. Norwell, Massachusetts: Kluwer Academic Publishers. Consultado el 19 de junio del 2008, de: http://books. Google.co.ve/books?idMUvlurkjwc8p gPA578dq=shinkfield+books8source 0bl8ots

Stake, R. (2006). Evaluación comprensiva y evaluación basada en estándares. Barcelona, España: Editorial Graó.

Sthenhouse, L. (1991). Investigación y desarrollo del currículo (3era. ed.). España: Ediciones Morata.

Sthenhouse, L. (1996). La investigación como base de la enseñanza (3era. ed.). España: Ediciones Morata.

Stufflebeam, D., y Shinkfield, J. (1987). Evaluación sistemática: Guía teórica y práctica. España: Paidós/MEC.

Suchman, E. A. (1967). Evaluative research: Principles and practice in public service and social action programs [Evaluación de la investigación: Principios y práctica en el servicio público y programas de acción social]. New York: Russell Sage Foundation.

Tenti Fanfani, E. (Compilador). (2006). El oficio de docente. Vocación, trabajo y profesión en el Siglo XXI. Buenos Aires: Editorial Ediciones Siglo XXI.

Tyler, R. W. (1949). Basic principles of curriculum and instruction [Principios básicos del curriculum y la instrucción]. Chicago: University of Chicago Press.

Von Glaserfeld, E. (1988). Introducción al constructivismo radical. En P. 
Watzlawick (Comp.), La realidad inventada: ¿Cómo sabemos lo que creemos saber? (pp. 20-37). Barcelona, España: Ediciones Gedisa.
Zabalza, M. (2007). Competencias docentes del profesorado universitario. Calidad $y$ desarrollo profesional (2da. ed.). Madrid: Ediciones Nancea, S. A. 